\title{
Stay or Leave Abusive Dating Relationships: Portuguese Victims' Reasons and Barriers
}

\author{
Sónia Caridade ${ }^{1,2,3, *(\mathbb{D})}$, Inês Pinheiro ${ }^{1}$ (D) and Maria Alzira Pimenta Dinis ${ }^{2,4,5}$ (D) \\ 1 Faculty of Human and Social Sciences, University Fernando Pessoa (UFP), 4249-004 Porto, Portugal; \\ 29799@ufp.edu.pt \\ 2 Permanent Observatory Violence and Crime (OPVC), University Fernando Pessoa (UFP), 4249-004 Porto, \\ Portugal; madinis@ufp.edu.pt \\ 3 Interdisciplinary Center for Gender Studies (CIEG), Higher Institute of Social and Political Sciences, \\ University of Lisbon (ISCSP-UL), 1300-663 Lisboa, Portugal \\ 4 Faculty of Science and Technology, University Fernando Pessoa (UFP), 4249-004 Porto, Portugal \\ 5 UFP Energy, Environment and Health Research Unit (FP-ENAS), University Fernando Pessoa (UFP), \\ 4249-004 Porto, Portugal \\ * Correspondence: soniac@ufp.edu.pt
}

Received: 30 April 2020; Accepted: 13 May 2020; Published: 15 May 2020

\begin{abstract}
The decision to stay or leave an abusive relationship is multifactorial and frequently involves a cyclic process involving several phases. This article presents a qualitative analysis regarding the reasons and barriers to stay or leave an abusive dating relationship, as well as the challenges that it implies. A semi-structured, in-depth interview was used to collect data from thirteen dating victims, aged $17-30$ years and mainly female $(n=12)$. The emotional and affective dependence of the partner and the belief that behaviour may change emerge as the main reasons presented by the victims to remain in an abusive relationship. Shame, fear of losing the partner, and failure to recognize the abusive relationship were reported as the main barriers to leave the abusive relationship, thus making it difficult to seek help. Understanding reasons to stay in, or barriers to leave, an abusive relationship is fundamental to promoting help-seeking behaviours in victims of dating violence (DV), particularly in the case of young people, since it has serious implications in the developmental pathway of this age group.
\end{abstract}

Keywords: dating violence (DV); victims of dating violence; young people; leave abusive relationships; stay in abusive relationships; help-seeking

\section{Introduction}

Violence in intimate relationships is a pervasive social problem that has persisted for several decades and continues to show high prevalence indicators in several European countries (European Union Agency for Fundamental Rights FRA), including Portugal (e.g., Azambuja et al. 2013; Lisboa et al. 2009; Lisboa 2016). Lisboa et al. (2009) conducted one of the most important studies on violence against women and men, having found that $38 \%$ of interviewed women aged 18 or more had experienced at least one type of physical, psychological or sexual violence, with $41.7 \%$ of the offenses being perpetrated by the husband/partner. The results of this important Portuguese research revealed that violence in intimate relationships was a hidden reality, strongly conditioned by the dominant system of values, norms and social models, thus increasing a progressive interest on the part of the scientific community to explore this problem. Since then, several additional Portuguese (e.g., Machado et al. 2010; Neves et al. 2016; Santos and Caridade 2017) studies were developed, documenting the higher prevalence of dating violence (DV), and demonstrating that it is a widespread problem. Other international studies 
(e.g., Hamby and Turner 2013; Haynie et al. 2013; Jennings et al. 2017; Straus 2004) and important international organizations-such as the Center for Disease Control and Prevention (2016) and the World Health Organization (2016) — recognize DV as a serious social and public health issue. DV is defined in this study as the use or threat of violence, in its most varied typologies, i.e., physical, emotional/psychological and sexual, over another person, with whom the subject maintains a relationship of proximity and intimacy (Caridade 2016).

One of the largest intercultural studies on DV, conducted by Straus (2004), and involving 31 universities from 16 countries, reported that the indicators of physical violence in dating relationships may range from $17 \%$ to $45 \%$ in the last year of dating participants. Another study on the prevalence of DV, developed by Haynie et al. (2013), and based on a representative sample of 2203 students, found values of victimization (35\%) and perpetration (31\%) of concern. Equally disturbing are the data collected by the Center for Disease Control and Prevention (2016) in the United States, estimating that one in five girls and one in seven boys suffered some form of intimate violence between 11 and 17 years of age. A systematic review by Jennings et al. (2017), involving 169 studies and conducted with young people aged 15 to 30 years old, found lower prevalence estimates among younger $(<10 \%)$, when compared to older people (between $20 \%$ and $30 \%$ ), with women reporting higher indicators of victimization. In Portugal, a study conducted with young people, involving a large sample of 4665 participants (Machado et al. 2010), found that one in four young people reported having experienced at least one episode of DV throughout life. In another study developed by Guerreiro et al. (2017), carried out with a sample of 2500 young people aged between 12 and 18 years old, $7 \%$ of the participants acknowledged to having been the target of DV, at least once.

The literature also shows that young adults tend to experience and perpetrate more than one type of DV (e.g., psychological, verbal, sexual violence) in the same or in different situations (Hamby and Turner 2013). Nevertheless, within the context of DV, psychological violence has been identified as the most prevalent type of abuse, when compared to others abusive typologies. A study developed by Fernandéz-González et al. (2014), Spain, found high rates of DV, concluding that psychological violence is the most prevalent abusive typology $(90 \%)$, followed by physical violence $(40 \%)$ and finally, by sexual abuse (reported by $27.1 \%$ males and $10.9 \%$ females). In Portugal, Guerreiro et al. (2017) found that psychological violence emerged as having been the most prevalent type of violence in dating relationships $(8.5 \%)$, followed by physical violence $(5 \%)$ and by sexual violence (4.5\%). These results corroborate the ones from Machado et al. (2010) study, in Portuguese context. Another relevant study conducted in the Portuguese context by the Alternative Women's Union and Response (UMAR) (2019), with a large sample of 4938 young people from all districts of Portugal, concluded that $67 \%$ of the total of young people legitimize at least a behaviour of violence, and $58 \%$ of young people reported having experienced at least one of the forms of violence listed in the study's questionnaire.

The international scientific research has also been documenting the adverse impacts of DV on young people's development. Several studies (e.g., Exner-Cortens et al. 2013; Foshee et al. 2013; Shorey et al. 2012) have shown that DV is positively associated with a wide range of behavioural, emotional and mental health problems in the long-term, which may include substance use, depression and anxiety, post-traumatic stress disorder, suicidal ideation, poor academic performance or even involvement in antisocial and risky sexual behaviours, along with other forms of interpersonal violence. These consequences may differ, according to the gender of the victim, with girls tending to exhibit more internalization problems (e.g., eating disorders, low self-esteem and emotional distress, panic attacks, alcohol consumption, depressive symptomatology, suicidal thoughts or smoking) (e.g., Ackard et al. 2007; Romito and Grassi 2007) and boys expressing more externalizing problems (e.g., involvement in antisocial behaviour, suicidal ideation, panic attacks or substance use) (Romito and Grassi 2007).

DV help-seeking is of crucial importance to mitigate the risks associated with young people's mental health, improving conflict negotiation and anger management skills, as well as to develop strategies 
for self-protection and prevention of future violence (Caridade 2018). The decision to leave an abusive relationship implies that victims of DV identify and recognize the existence of relational problems, and seek external assistance that could involve the choice of formal (e.g., Criminal Police Authorities, health professionals and teachers) or informal (e.g., family, peers) (Liang et al. 2005) support. The literature demonstrates that young people show a reluctance to ask for help (e.g., Gallopin and Leigh 2009; Moore et al. 2015), anticipating possible barriers to effective support. It has been argued that victims can anticipate a negative response (e.g., judgment, overvaluation or devaluation, depreciation, blaming the victim, suggestion to end the relationship) from the source of disclosure to which they intend to seek help (Gallopin and Leigh 2009). A systematic review of Moore et al. (2015) that sought to identify the supports and barriers inherent to the disclosure of the abusive situation concluded that, in general, there are actually few resources/support services available for victims of DV, which may partially explain the fact that young people mainly resort to informal support, that is, parents, peers and other educators. The stigma associated with DV, as well as the absence of screening and assistance protocols for young people involved in abusive dating relationships, are other barriers in accessing formal support services. Another systematic review developed by Pinheiro and Caridade (2019) about request for help in young adults who have experienced DV concluded that victims prefers to use informal sources to disclose DV, thus favouring peers. In the same review, female victims emerged as those showing a greater trend to disclose DV, while also emerging as those who provide more support to victims. Furthermore, in the same review, multiple barriers were identified to disclose DV (e.g., legitimacy of violence, fear of losing partner, shame and self-sufficiency to solve the situation). Other authors (e.g., Sabina and Ho 2014) report the trend for young people to favour the use of informal sources, rather than more formal sources of disclosure, with the request for help essentially focusing on peers. Victims of DV rarely reveal violence to their parents, preferring to do it with peers, for fear of judgment and shame associated with exposing the abuse situation to their parents (Gallopin and Leigh 2009). In a qualitative study, Shen (2011) interviewed ten Taiwan female victims of DV, in order to identify and understand the cultural meanings and barriers that may interfere with help seeking behaviours and six main factors were found: (i) self-reliant culture, (ii) personal and family shame, (iii) secretive and sexual dating relationships, (iv) fear of negative reactions from others, (v) unfamiliarity with available resources, and (vi) revictimization in seeking help. Another qualitative study by Baley (2010) with only six participants found that the participants' reports tend to reflect aspects of broader susceptible cultural or social discourses, with some of them (e.g., discourses of romance and femininity such as the importance of the woman's nurturing role in sustaining the relationship) promoting the maintenance in abusive relationship and others (e.g., discourses of self-reliance and responsibility for one's own actions and needs) helping participants to leave such relationships. The same study concluded that participants report different indicators of strength and agency in dealing with the abusive situation, thus reflecting different forms of intervention at different times. Enander and Holmber (2008) also emphasize the resistance of battered women in the description of the violent dynamics of the relationship, however this does not necessarily leading to leaving the relationship. They identify three overlapping leaving processes: (i) breaking up, involving the physical breakup action; (ii) becoming free, which covers emotion (e.g., love, hate, compassion, hope) and involving release from the strong emotional bond to the batterer, and (iii) understanding, which is related to cognition, in which the woman perceives and interprets the abusive situation in which she was involved. Finally, it is important to highlight that the victim's decision to stay or leave is a multidimensional one (Barnett 2000), involving a complex process usually characterized by a leave/return cycle consisting of several phases, such as: (i) resistance and management of abusive situations; (ii) recognizing abuse and reformulating/reinterpreting behaviours as abusive or not; (iii) "break free", disengage, focusing on the victim's own needs (Anderson and Saunders 2003). 


\section{Research Aim}

The present study sought to identify the abusive typologies experienced by victims of DV, aiming to identify and understand the factors that lead victims to stay in the abusive relationship and barriers to help-seeking or to leaving that abusive relationship, as well as the challenges that it implies. In this sense, seeking to understand the victim's reasons and the process inherent to the decision to remain in or leave an abusive relationship, is essential for the support provided to DV victims, as well as to mitigate the consequences/effects that may arise for their welfare. Although there are already some Portuguese studies documenting the disturbing indicators of DV among young people in Portugal (e.g., Caridade 2018; Guerreiro et al. 2017; Machado et al. 2010; Neves et al. 2016; Santos and Caridade 2017), specific studies conducted with DV victims are scarce in the context of Portuguese reality. In addition, other Portuguese studies (e.g., Cerejo 2014; Pinto 2018) that have attempted to analyse the reasons for maintaining or leaving abusive relationships mainly focus on marital relationships.

\section{Methods}

The research design was qualitative, exploratory, using a purposive sampling method and semi-structured and in-depth interviews that were subjected to content analysis. The option for a qualitative approach is due to the fact that it allows better access to the perceptions of DV victims, as strongly defended by other authors in this field, such as Shen (2011), who also used it in similar studies.

\subsection{Participants}

As it happens in other relevant qualitative studies in this field (e.g., Baley 2010; Enander and Holmber 2008; Rosen and Stith 1995; Shen 2011), respectively, with six, ten, eleven, and ten participants each, this study comprised a small sample, consisting of 13 participants, mostly female (92\%), according to the following inclusion criteria: (a) participants were DV victims and all participants had already ended the abusive relationship at the time of the interview; (b) participants should be between 16 and 30 years old. The age of participants ranged from $17-30$ years of age $(M=25$ and $S D=3.66$ years old). In terms of victims' education, one completed the basic schooling (8.0\%), two completed the 9th grade $(15.4 \%)$, six completed the 12 th grade $(46.0 \%)$, two with university degree $(15.4 \%)$ and two with master degree (15.4\%). A significant number of respondents (92.3\%) identified participants as being heterosexual and only one respondent reported to be homosexual. The duration of the relationship varies between one year and thirteen years (Table 1).

Table 1. Participants' characteristics $(n=13)$.

\begin{tabular}{llcc}
\hline ID & Age & Education & Duration of Relation (Years) \\
\hline P1 & 23 & 12th grade & 4 \\
P2 & 23 & Degree & 3 \\
P3 & 26 & 12th grade & 2 \\
P4 & 29 & 9th grade & 13 \\
P5 & 28 & 6th grade & 2 \\
P6 & 26 & Master & 6 \\
P7 & 30 & 12th grade & 4 \\
P8 & 27 & Master & 3 \\
P9 & 22 & Degree & 2 \\
P10 & 24 & 9th grade & 4 \\
P11 & 25 & 12th grade & 8 \\
P12 & 17 & 12th grade & 1 \\
P13 & 30 & 12th grade & 5 \\
\hline
\end{tabular}

\subsection{Procedure}

The study was initially approved by the institutional Ethics Committee. For the enrolment of the participants, it became necessary in the first stage, to contact through electronic email, different victim 
support institutions, which were informed of the purposes of the present study. All the contacted institutions agreed to cooperate in this study, and during 5 months of announcements, 25 persons requested details about the study. After explaining the study in detail, 15 of these 25 persons agreed to participate in the study. Of those 15, 13 participants met the eligibility criteria and were thus interviewed. The two excluded subjects had already perpetrated violence on dating partners.

After obtaining the informed consent of the participants, the interviews were conducted in the facilities of the support institution and also in a room of the university where the study was carried out, specifically reserved for that purpose. The interviews had a duration ranging from 45 to $120 \mathrm{~min}$ and were carried out by researchers with experience in interviewing victims and with specific training in the scope of DV. Due to the possibility of dealing with potentially disturbing experiences, participants were also warned of the possible psychological consequences of the interview. Where necessary, and in the interest of the participants, further specialized support was also made available. The interviews were recorded using a digital audio and were verbatim transcribed in order to preserve the integrity of the reports, aiming further analysis.

\subsection{Measure}

For the collection of data, semi-structured, in-depth interviews, with an interview guide to collect qualitative data, developed for this specific purpose and consisting of six sections, were used. In the first section, the perception of the respondents about the notions of dating and love was explored; the second section is intended to identify and characterize the participants' knowledge regarding the DV problem, namely the identification of abusive typologies associated with DV, the extent of abuse, motivations for the use of violence by the aggressor, and consequences for the victim and aggressor. The third section is intended to characterize abusive experiences and their dynamics. In the fourth section, the participants were asked about the motivations for staying in abusive relationships and the barriers to DV disclosure. The fifth section referred to the reasons for the disclosure of the abusive situation by the participants and, on the type of sources required, either informal or formal, the reason for the DV disclosure or non-disclosure and the types of support provided. Finally, the sixth section took the assessment of the effectiveness of DV disclosure in resolving dating abuse situations into account. Participants were also asked to complete a sociodemographic questionnaire to characterize them in terms of gender, age and duration of relationships. Only Sections 3 and 4 of the interview guide are presented in this paper.

\subsection{Data Analysis}

Thematic data analysis, which is based on a constructionist perspective, was used. It allows understanding the phenomenon under analysis, its meaning and the way it is experienced, socially constructed and reproduced, as highlighted by Braun and Clarke (2006). The inductive coding procedure was adopted. The themes identified were strongly connected to the data, not attempting to adjust to a pre-existing coding framework, according to what is also advocated by the same authors. The coding was as inclusive as possible, to avoid concealing any potentially important extract in the theme. Various strategies were employed to help ensure credibility and trustworthiness of data: (i) it was intended to ensure saturation of the characteristics of the participants in the sample; (ii) a more dense description of the results was carried out, and the entire coding process was audited by an experienced researcher; (iii) throughout the process, from recruitment to interviewing and data analysis, researchers have always sought to reflect and debate data, sharing preliminary impressions.

\section{Results}

\subsection{Typologies of DV and Help-Seeking Behaviours}

The experience of psychological/verbal violence was reported by all victims $(n=13)$, then followed by physical violence $(n=12)$, with the exception of participant P11, who did not identify the latter form 
of abuse. The social violence, reported by eight participants, involved the restriction and prohibition to establish social contacts with peers, even with parents. Stalking $(n=3)$, sexual violence $(n=2)$ and economic violence $(n=1)$ were the least reported abusive violence typologies by participants. All the participants who acknowledged to disclose DV $(n=10)$, chose to do so through informal sources such as peers $(n=6)$, parents $(n=2)$, mother $(n=2)$ and siblings $(n=1)$. Only five participants reported having also sought formal sources help such as the police $(n=4)$, teachers $(n=1)$ and health (medical) professionals $(n=1)$ (Table 2$)$.

Table 2. Participants' help-seeking behaviour and type of experienced dating violence $(n=13)$.

\begin{tabular}{cccc}
\hline ID & Help-Seeking: Yes or No & Help-Seeking Source & Type of Dating Violence Experienced \\
\hline P1 & Yes & Peers/Police & Psychological/verbal; physical; social and stalking \\
P2 & No & - & Psychological/verbal and physical \\
P3 & Yes & Peers, Professional & Psychological/verbal; physical; social and sexual \\
P4 & No & - & Psychological/verbal and physical \\
P5 & Yes & Peers, Parents & Psychological/verbal; physical and social \\
P6 & No & - & Psychological/verbal and physical \\
P7 & Yes & Mother & Psychological; physical and social \\
P8 & Yes & Sibling & Psychological/verbal; physical; social and economic \\
P9 & Yes & Peers & Psychological/verbal; physical and social \\
P10 & Yes & Parents, Police & Psychological/verbal; physical; stalking and social \\
P11 & Yes & Peers, Teacher & Psychological; social and stalking \\
P12 & Yes & Mother, Police & Psychological/verbal and physical \\
P13 & Yes & Peers, Police & Psychological; physical and sexual \\
\hline
\end{tabular}

\subsection{Reasons to Stay in Abusive Dating Relationships}

Victims of DV identify five main reasons to stay in abusive relationships (Table 3).

Emotional dependence. Considering the discourses of the twelve participants, emotional dependence is the main reason for remaining in an abusive relationship. In this sense, one victim identified the "blind love" she felt for her partner and that led her to believe that this would be the partner for the entire life, P9: "I was crazy about him, he was the man I thought he was going to be for my whole life". "Sick love" was also identified by two other victims as the reason for maintaining the abusive relationship, P11: "The biggest reason, without being hypocritical, was undoubtedly to like him", P8: "It was a sick love"; or, as mentioned by P12, the fact that the partner had the characteristics that she idealized "Because he had everything I was looking for in someone ... He was a beautiful boy, he was the one.".

Change the behaviour offender beliefs. Nine victims justified their investment and maintenance in the dating relationship, based on the hope that, one day, the partner would change the behaviour. As the speech of P10 demonstrates: "I lost count of the times I cried, I begged, I waited for him to change him back to what he was", the belief in changing the abusive behaviour of the partner allowed to manage all the suffering experienced. P12 invoked the positive experiences of the beginning of the dating relationship, namely the most favourable characteristics of the partner, to legitimize the expectations that the behaviour would change and the violence would cease- "I thought he was going to change, because at the beginning of the relationship he was an impeccable boyfriend, I couldn't imagine anyone better. I was hoping that he would ever get better so I couldn't be accusing him, because he could get better. And I thought it was actually my fault and not his". P9, in turn, focused on the individual characteristics of the partner to legitimate his abusive conduct, feeding the belief in change: "I thought he was going to change, because he said he was going to change and that it was going to stop. I thought, that it was with nerves that he did that and that he liked me a lot and that I was the love of his life and that I was the woman for his life and then I apologized once, twice, ten and 20 times, you don't even count the countless times I apologized."

Partner dependence. According to four participants, dependence on the partner forced the participant to maintain the abusive relationship. A victim objectively identified the fact that she was pregnant and wanted her daughter to benefit from the father's presence in her development, P3: "My priority in being with him was that my daughter needed a present father. What would become of her without a father?". P4 also 
identified the existence of children and the fact that she did not want to separate them from the father figure, as a justification for maintaining the connection to the abusive partner, also adding the financial dependence of the partner and her difficulty in being able to meet the needs of her four children alone, P4: "Perhaps the strongest reason were my children! because I had in my mind that I couldn't separate them from the father. That wasn't fair to them! And then also the financial condition, because I was banned from working because it was useful! And as such it was complicated to leave the house like this with our children without anyone because I had no family background". The fear of the implications of the children not living with the father was also identified by P11: "First, that my daughters didn't grow up without a father and second, I never complained because I didn't want to be the reason why their father was in jail".

Social pressure. Two victims identified the pressure from the family, as having been the source of maintaining the abusive relationship. P11 alluded to the pressure exerted by the mother: "My mother used to say that it was the life that I chose and that I had to endure it... It would be a shame to separate". P13 identified the fact that her partner's family legitimized the abusive relationship because she was pregnant: "Because his family said that I should be with him, and that it was shameful to be a single mother".

Feeling of guilt. The maintenance of the abusive relationship also emerged, supported by feeling of guilt by two victims, P4: "Either it was out of jealousy, or it was because I came upset and I even thought it was my fault" and P11: "My mother knew everything and she said it was the life that I had chosen, I had to tolerate it as she also tolerated it."

Table 3. Reasons to stay in abusive dating relationships.

\begin{tabular}{cccccc}
\hline ID & $\begin{array}{c}\text { Emotional } \\
\text { Dependence }\end{array}$ & $\begin{array}{c}\text { Belief in } \\
\text { Change }\end{array}$ & $\begin{array}{c}\text { Partner } \\
\text { Dependence }\end{array}$ & $\begin{array}{c}\text { Social } \\
\text { Pressure }\end{array}$ & $\begin{array}{c}\text { Feeling of } \\
\text { Guilt }\end{array}$ \\
\hline P1 & $X$ & $X$ & & & \\
P2 & $X$ & $X$ & $X$ & & \\
P3 & $X$ & $X$ & $X$ & & \\
P4 & & $X$ & & \\
P5 & $X$ & $X$ & & \\
P6 & $X$ & $X$ & & \\
P7 & $X$ & $X$ & & \\
P8 & $X$ & $X$ & & & \\
P9 & $X$ & $X$ & & \\
P10 & $X$ & $X$ & & \\
P11 & $X$ & $X$ & & \\
P12 & $X$ & $X$ & & \\
P13 & X & X & & \\
Total & X & 9 & & & \\
\hline
\end{tabular}

\subsection{Barriers to Help-Seeking or Leave Abusive Dating Relationships}

Participants identified different barriers to help-seeking before (i.e., from the moment they did search for help) or during the abusive relationship, which constrained their leaving, as indicated in Table 4.

Threats. Five participants identified threats to themselves or others, namely family, as one of the main obstacles to seek help and leave abusive relationships. Thus, P1 claimed that her various efforts to end the relationship were followed by threats to her physical integrity, P1: "I tried to break up with him off and he said it would happen to me like the case of a boyfriend who hit his girlfriend with an axe on the head and I was afraid, I had no one to turn to. So, I stayed with him because he was completely psychopathic. He was waiting for me at the door behind the trash can". P5 also identified threats directed at her and her immediate family members as obstacles to ask for help and leave the abusive relationship: "He threatened to kill me and my parents and sister". The fear that the partner would comply with the threats made was identified by P1 as an instigator of inaction in the face of the abusive situation: "It was threats and fear. I was very afraid. He said that if I told someone, if I complained about him or if he knew that someone knew what was happening, that he was going to kill me. It was fear. It was out of fear that I didn't 
report" and for P13: "I lived in fear that something would be done to me because he said he was going to kill me ... I had no family support. I was alone and I was ashamed".

Fear of losing partner. Four participants justified their difficulty in asking for help and leaving the abusive relationship, given the fear of losing the partner, because they were unable to find another dating partner, as it can be seen in the P2 statement: "I want him to stay with me and that's why I never even told anyone". Another victim identified the implications that disclosure of the abusive situation could have on the physical distance of the partner, P9: "First of all, I didn't want to leave him, it's true, I didn't want to leave him for anything. For example, if I told my mother what could happen is that she was going to press charges and that was unthinkable for me. I didn't want him any harm. I wanted him to stay with me and I never even told anyone and I suffered for myself". P8 also mentioned the suffering she was subjected to in order to preserve her dating relationship: "... I was humiliated, and I subjected myself, for example, to betrayals so as not to lose him".

Shame. Shame also emerged as an indicator of embarrassment in the request for help, in the shame of facing others and taking on abusive dating experiences, as shown by the P8 and P4: "That was always the shame! We are ashamed to admit what we have been through! And as long as we haven't changed our thinking, we believe things will change! And that is completely wrong". Another victim, P13, mentioned the shame of assuming herself as a single mother: "It was shameful to be a single mother".

Consequences for the partner. The request for help has consequences for the abusive partner, something that three participants identified as having motivated their decision not to seek help, blocking them from leaving the abusive relationship. More specifically, P9 and P12 alluded to the implications that the complaint could have on the partner, e.g., P12: "I didn't report him because I ended up always apologizing and I didn't want anything to happen to him" and P11 considered the fear that the partner could be arrested: "I never complained because I didn't want to be the reason he was in jail".

Non-recognition of violence. Failure to identify the abusive situation was pointed out by three participants. Specifically, one participant identified the difficulty to recognize psychological aggression, e.g., P2: "I never thought that what I suffered was violence. Physical violence is something palpable, the psychological is not seen. If you do not see it, it is okay" and P7 talked about confusing abusive behaviour with demonstrations of love: "I thought that what was happening was love".

Lack of support. Two participants identified the lack of social support or the reduced effectiveness and availability of their support network to assist in the management of the abusive situation, as observed in the statements of P13: "My mother asked me if I was sure I wanted to press charge, she said to think better", and P6: "I didn't have a lot of close family, my elder brother had died years before, I have a chronic depressive mother and an absent father"

Table 4. Barriers to help-seeking or leave abusive dating relationships.

\begin{tabular}{|c|c|c|c|c|c|c|c|}
\hline ID & Threat & $\begin{array}{l}\text { Lose } \\
\text { Partner }\end{array}$ & Shame & $\begin{array}{c}\text { Consequences for } \\
\text { Partner }\end{array}$ & $\begin{array}{l}\text { Non-Recognition } \\
\text { of Violence }\end{array}$ & $\begin{array}{l}\text { Lack of } \\
\text { Support }\end{array}$ & $\begin{array}{l}\text { Knowledge } \\
\text { of Parents }\end{array}$ \\
\hline $\mathrm{P} 1$ & $x$ & & & & & & $x$ \\
\hline $\mathrm{P} 2$ & & $x$ & $x$ & & $x$ & & \\
\hline P3 & $x$ & & & & & & \\
\hline P4 & & & $X$ & & & & \\
\hline P5 & $x$ & & & & & & \\
\hline P6 & & & & & & $x$ & $x$ \\
\hline P7 & & & & & $x$ & & \\
\hline P8 & $x$ & $x$ & $x$ & & & & \\
\hline P9 & & $x$ & & $x$ & & & \\
\hline P10 & & & & & $x$ & & \\
\hline P11 & & & & $X$ & & & \\
\hline P12 & & $X$ & & $X$ & & & \\
\hline P13 & $X$ & & $x$ & & & $x$ & \\
\hline Total & 5 & 4 & 4 & 3 & 3 & 2 & 2 \\
\hline
\end{tabular}


Knowledge of parents. The fear of parents' reaction towards DV was also identified by two participants, P1: "If my parents found out, they would never let me leave the house or have someone" and P7: "I was afraid my parents would know and there was a disgrace."

\subsection{Leaving Abusive Relationships: "Break Up" Challenges}

Of the total of victims interviewed, ten assumed to disclose DV: eight did so during the abusive relationship and two victims only disclosed DV after the end of the relationship. All participants had, at the time of the interview, already left the abusive relationship. Despite the several reports about maintaining abusive relationships and the difficulties expressed by the victims in leaving the abusive partner and seeking help, it was also possible to identify other agency discourses that would eventually contribute to encouraging the decision to "break up" the abusive relationship. Thus, two participants pointed out the public disclosure of their abusive situation as having been crucial to prevent possible setbacks in their decision making to leave the abusive partner, P1: "I needed people to know everything, so they would not make me go back to that person" or as a way to limit possible implications on future relationships, P5: "I only felt ready to speak at that time and then my past would be interfering with relationships I could have after this".

The participants also reported the need to be aware of what a healthy relationship implies, namely that it should involve respect, love, complicity, equality as it is possible to observe in the following excerpts: P6: "A companionship, a mutual assistance based on respect and complicity that has to override even the feelings, much more than a union of interests", P3: "There is support, which is due to the support of men or women ... There is equality. But above all respect, as it is evident", P9: "To me, an ideal love is to have a man that I have confidence in, that respects me, that is by my side when I need him, both in bad times and in good time. The one who have the same life goals and who want the best for us two. Affection, love, respect, trust, understanding the other person and being patient when something is not right. I don't believe in love for life, but I believe in wanting things to work".

The speeches of the victims also signal their ability to re-evaluate and reinterpret the abusive situation in which they were involved, the recognition of the negative implications that the abusive behaviour had on their well-being and the importance of showing a level of self-reliance in relation to meeting their own needs. Some of the participants' speeches in this regard are mentioned: P2: "The most important thing is to like ourselves and if we subject ourselves to suffering for behaviours that we don't agree with, we shouldn't be like that", P3: "At first I thought that [that it was best to be with him] but then I started to realize that it was not living, that it was not good for me, that it brought me suffering", P4: "Until I changed! Yes, it was I who had to change my thinking and say I didn't want that anymore! Because as long as our thinking doesn't change, it's no use doing anything and we always come back to the same", P5: "I left, because no, we are not obliged to subject ourselves to inappropriate behaviour on the part of anyone. I didn't stay, I made a decision that I knew it would cost me a lot but I left the house. I knew that if I continued, there I would be another victim in the statistics and I had to think about my daughter", P10: "I got rid of a monster and managed to have life goals, self-esteem, and self-esteem did not return overnight. I started dreaming again, dreaming that I had a future".

\section{Discussion}

The present study involved a sample of Portuguese DV victims, who reported experiencing several abusive DV typologies (psychological/verbal, physical, sexual, stalking, social and economic violence). This qualitative study makes an important contribution to deepening the knowledge of DV in Portugal, considering the fact that a vast majority of Portuguese studies use a quantitative design, involving young people of the general population and studies focusing on victims alone are extremely scarce (Caridade and Dinis 2020) or mainly focus on marital relationships, since other Portuguese studies such as the one of (Cerejo 2014; Pinto 2018). Therefore, this study is also useful to better support preventive and interventional policies in this field. 
The typology of psychological/verbal abuse was the most reported by the interviewed DV victims, which is in accordance with what was verified by other previous relevant international (e.g., Fernandéz-González et al. 2014; Straus 2004) and Portuguese studies (e.g., Guerreiro et al. 2017; Machado et al. 2010; Santos and Caridade 2017).

The majority of the participants in this study assumed to have been forced to ask for help at some point, as also found in the study developed by Edwards et al. (2012). This is contrary to what has been documented in other international studies (Gallopin and Leigh 2009; Moore et al. 2015), reporting the reluctance of young people to reveal the abusive situation in which they are involved. The request for help was mainly made to informal sources, such as family and friends. Other international studies (Edwards et al. 2012; Gallopin and Leigh 2009; Sabina and Ho 2014) have also documented the preference of young people to disclose DV to informal sources, as well as the greater reluctance of young people to report DV abuse to the official authorities (Caridade et al. 2019; Pinheiro and Caridade 2019).

The present study allows us to verify that the decision to stay or leave an abusive relationship is influenced by several factors, demonstrating the multidimensional character previously advocated by Barnett (2000), and involving a process with various phases (Enander and Holmber 2008). In this sense, the victims' decisions to remain in an abusive relationship seem to be based primarily on psychological factors such as the emotional dependence on the offender, followed by beliefs in being able to change the offender's behaviour, and feelings of guilt, corroborating previous studies, such as the one from Anderson and Saunders (2003). The participants have also identified the partner's economic dependence and social pressure as external inhibiting factors that are associated with the decision of remaining in abusive relationships (Anderson and Saunders 2003; Barnett 2000). These are disturbing results, as the permanence of young people in problematic and violent relationships may contribute to the increased risk of a cycle of violence, occurring not only in the current relationship, but also in the future (Helm et al. 2015). These results seem therefore to indicate some existence of cultural meanings and barriers in the decision to stay, as also reported by Shen (2011).

Help-seeking is an important step in the process of leaving an abusive relationship. The interviewed DV victims in this study identified many barriers to the disclosure of abusive experience and which constrained the decision of leaving the relationship. The vast majority of factors pointed out by the victims are mainly related to interpersonal factors, such as threats to themselves or others, the fear of losing their partner, the feeling of shame, the consequences that disclosure will have on their partner or the failure to recognize the abuse situation, as supported by Liang et al. (2005). Other studies have also documented these barriers to DV help-seeking (e.g., Ameral et al. 2017; Edwards et al. 2012; Rueda et al. 2015). These results seem to support, in part, the thesis of the culture of self-sufficiency, and therefore the fact that the victims tend to try to solve the situations of victimization alone, either because of shame of assuming themselves as victims, or because they fear losing their privacy or even because they do not want to involve family and friends with matters of this nature, as reported by Shen (2011). The experience or perception of these obstacles may influence the victims' decision to seek help (Liang et al. 2005), leading many victims to remain in an abusive relationship for a long period of time, thus increasing the risk of revictimization and promoting the negative consequences associated with DV (Moore et al. 2015). However, in this study, other discourses were also found, such as self-reliance and focus on the abuse survivors' own needs and the re-evaluation of the abusive situation, which implies recognizing the abusive behaviour of the partner and its implications on the well-being of the victim. Together, this reflects some resistance and agency from abuse survivors to deal with the abusive situation and break up, as shown by other international studies (Baley 2010; Enander and Holmber 2008) in this field.

A more structured knowledge about the reasons that lead young people to stay or leave an abusive relationship, can assume a central role in the protection of victims, namely in the adoption of actions that facilitate the safe and permanent exit from the same abusive relationship, such as a specialized shelter for victims where they can stay, in order to guarantee their safety (Pinheiro and Caridade 2019). 
This study has some limitations that must be considered when assessing the results. As mentioned, the small size of the sample, common, as already mentioned, to other relevant studies in the field (e.g., Baley 2010; Enander and Holmber 2008; Rosen and Stith 1995; Shen 2011), is justified by the difficulty in accessing DV victims, which also hindered the construction of a more heterogeneous sample. The sample is mainly composed of heterosexual women $(n=12)$, involved in heterosexual relationships and all participants were already out of the abusive relationship at the time of the study. In view of the known difficulties of victims involved in same-sex relationships, related to sexual orientation and gender identity, that affect processes of seeking assistance (Calton et al. 2015), it is important that future studies also incorporate this specific population. This study focuses only on victims, which is opposite to other studies which address the general population, but it is important that future research also seeks to include offenders and participants who assume to have been involved in, or perpetrated, this type of abuse, in order to better understand the perpetuation of abusive relationships over time and the reasons behind late requests for help, intensifying the abuse situation. Further studies should also consider developing longitudinal mixed-methodologies with larger and more diverse samples whenever possible, in order to obtain a holistic understanding of the DV phenomenon. In addition, and considering the reasons pointed out by the victims to stay in abusive relationships, namely social pressure and feelings of guilt, it is still of considerable importance that further studies try to explore the cultural meanings and barriers associated with help-seeking behaviours. This knowledge will make it possible to enhance the support provided to victims and eventually to promote culturally sensitive interventions, as clearly highlighted by Shen (2011). Finally, it is important to develop additional research aiming to better understand the factors underlying the preference to seek help from informal sources, as well as the impact of social reactions on the sharing of DV events and experiences by abuse survivors.

\section{Conclusions}

The present study made it possible to overcome some important gaps in Portuguese scientific research in terms of the reasons and barriers inherent in the victim's decision-making process to stay or leave an abusive dating relationship. This study has identified the main reasons and barriers for staying or leaving abusive relationships (e.g., personal, social and relational) from the perspectives presented by victims of DV. The findings are an important contribution to prevention and intervention efforts, aiming to address the DV problem in Portugal, improving victim's assistance by encouraging help-seeking behaviours.

The findings from this study have important implications for DV screening and intervening. According to the results found in the present study, it is important to continue to invest in the awareness of young people about the phenomenon and encourage the recognition of abusive behaviours, helping victims to establish safer dating relationships and to identify the available resources and support to help deal with DV. Likewise, it is important to invest in actions that are mainly based on a logic of empowerment - that is, that encourage training and skills development, such as identifying their own and their peers' relationships as healthy or unhealthy in order to maintain a positive dating trajectory, identifying a relationship as abusive, and being able to seek help to end it safely.

Author Contributions: Conceptualization, S.C., data curation, I.P., data analysis, S.C., writing, S.C. and M.A.P.D., editing, M.A.P.D. All authors have read and agreed to the published version of the manuscript.

Funding: The authors received no financial support for the research, authorship, and/or publication of this article.

Conflicts of Interest: The authors declared no potential conflict of interest with respect to the research, authorship, and/or publication of this article. 


\section{References}

Ackard, Diann, Marla Eisenberg, and Dianne Neumark-Sztainer. 2007. Long-term impact of adolescent dating violence on the behavioral and psychological health of male and female youth. Journal of Pediatrics 151: 476-81. [CrossRef] [PubMed]

Ameral, Victoria, Kathleen Palm Reed, and Denise Hines. 2017. An analysis of help seeking patterns among college student victims of sexual assault, dating violence, and stalking. Journal of Interpersonal Violence, 1-25. [CrossRef]

Anderson, Deborah, and Daniel Saunders. 2003. Leaving and abusive partner. An empirical review of predictors, the process of leaving, and psychological well-being. Trauma, Violence, E Abuse 4: 163-91.

Azambuja, Mariana, Conceição Nogueira, Sofia Neves, and João Nogueira. 2013. Gender violence in Portugal: Discourses, knowledges and practices. Indian Journal of Gender Studies 20: 31-50. [CrossRef]

Baley, Andrew. 2010. Leaving abusive relationships: Constructions of self and situation by abused women. Journal of Interpersonal Violence 25: 2297-315. [CrossRef]

Barnett, Ola. 2000. Why battered women do not leave, Part 1: External inhibiting factors within Society. Trauma, Violence, E Abuse 1: 343-72.

Braun, Virginia, and Victoria Clarke. 2006. Using thematic analysis in psychology. Qualitative Research in Psychology 3: 77-101. [CrossRef]

Calton, Jenna, Lauren Bennett Cattaneo, and Kris T. Gebhard. 2015. Barriers to help seeking for lesbian, gay, bisexual, transgender, and queer survivors of intimate partner violence. Trauma, Violence, $\mathcal{E}$ Abuse 15: 585-600.

Caridade, Sónia. 2016. Violência no namoro [Dating Violence]. In Dicionário Crime, Justiça e Sociedade. Edited by Rui Maia, Laura Nunes, Sónia Caridade, Ana Sani, Rui Estrado, Cristiano Nogueira, Hélder Fernandes and Ligia Afonso. Lisboa: Edições Sílabo, pp. 527-30.

Caridade, Sónia. 2018. Violência no namoro: Contextualização teórica e empírica [Dating violence: Theoretical and empirical contextualization]. In Violências No Namoro [Dating Violence]. Edited by Sofia Neves and Ariana Correia. Maia: Edições ISMAI, pp. 9-40.

Caridade, Sónia, and Maria Alzira Pimenta Dinis, eds. 2020. Adolescent dating violence: Outcomes and future challenges. In Adolescent Dating Violence: Outcomes, Challenges and Digital Tools. Hauppauge: Nova Science Publishers, pp. 1-18.

Caridade, Sónia, Inês Pinheiro, and Maria Alzira Pimenta Dinis. 2019. Disclosure in victims of dating violence: Strategies and reasons for help-seeking. In Dating Violence: Prevalence, Risk Factors and Perspectives. Edited by Wanda Spencer. New York: Nova Science Publishers, Inc., pp. 85-106.

Center for Disease Control and Prevention. 2016. Understanding Teen Dating Violence. Fact Sheet. 2016. Available online: http://www.cdc.gov/violenceprevention/pdf/teen-dating-violencefactsheet-a.pdf (accessed on 13 April 2020).

Cerejo, Sara Dalila Aguiar. 2014. Viver Sobrevivendo: Emoções e Dinâmicas Socioculturais nos Processos de Manutenção das Relações Conjugais Violentas. Living Surviving: Emotions and socio-Cultural Dynamics in the Maintenance of Violent Marital Relationships. Lisboa: FCSH, UNL.

Edwards, Katie, Christina Dardis, and Christine Gidycz. 2012. Women's disclosure of dating violence: A mixed methodological study. Feminism \& Psychology 22: 507-17.

Enander, Viveka, and Carin Holmber. 2008. Why does she leave? The leaving process(es) of battered women. Health Care for Women International 29: 200-26. [CrossRef]

European Union Agency for Fundamental Rights (FRA). 2014. Violence against Women: An EU-Wide Survey. Austria: European Union Agency for Fundamental Rights.

Exner-Cortens, Deinera, John Eckenrode, and Emily Rothman. 2013. Longitudinal associations between teen dating violence victimization and adverse health outcomes. Pediatrics 131: 71-8. [CrossRef]

Fernandéz-González, Liria, K. Daniel O’Leary, and Marina Julia Muñoz-Rivas. 2014. Age-related changes in dating aggression in Spanish high school students. Journal of Interpersonal Violence 29: 1132-52. [CrossRef] [PubMed] 
Foshee, Vangie, Heath Luz Reyes, Nisha Gottfredson, Ling-Yin Chang, and Susan Ennett. 2013. A longitudinal examination of psychological, behavioral, academic, and relationship consequences of dating abuse victimization among a primarily rural sample of adolescents. Journal of Adolescent Health 53: 723-9. [CrossRef] [PubMed]

Gallopin, Colleen, and Laila Leigh. 2009. Teen perceptions of dating violence, help-seeking, and the role of schools. The Prevention Researcher 16: 17.

Guerreiro, Ana, Ana Margarida Teixeira, Ana Teresa Dias, Cátia Pontedeira, Joana Cordeiro, Maria José Magalhães, Micaela Silva, Patrícia Ribeiro, and Tatiana Mendes. 2017. Violência no namoro: Resultados nacionais apontam a gravidade do Problemas [Dating violence: National Results Point to the Seriousness of the Problems]. Porto: UMAR-União de Mulheres Alternativa e Reposta.

Hamby, Sherry, and Heather Turner. 2013. Measuring teen dating violence in males and females: Insights from the national survey of children's exposure to violence. Psychology of Violence 3: 323-39. [CrossRef]

Haynie, Denise, Tilda Farhat, Ashley Brooks-Russell, Jing Wang, Brittney Barbieri, and Ronald Iannotti. 2013. Dating violence perpetration and victimization among US adolescents: Prevalence, patterns, and associations with health complaints and substance use. Journal of Adolescent Health 53: 194-20. [CrossRef] [PubMed]

Helm, Susana, Charlene Baker, Jeffrey Berlin, and Shaye Kimura. 2015. Getting in, being in, staying in, and getting out: Adolescents' descriptions of dating and dating violence. Youth \& Society, 1-23. [CrossRef]

Jennings, Wesley, Chidike Okeem, Alex Piquero, Christine Sellers, Delphine Theobald, and David Farrington. 2017. Dating and intimate partner violence among young persons ages 15-30: Evidence from a systematic review. Aggression and Violent Behavior 33: 107-25. [CrossRef]

Liang, Belle, Lisa Goodman, Pratyusha Tummala-Narra, and Sarah Weintraub. 2005. A theoretical framework for understanding help-seeking processes among survivors of intimate partner violence. American Journal of Community Psychology 36: 71-84. [CrossRef]

Lisboa, Manuel. 2016. Do privado ao público: Os caminhos da igualdade de género nas últimas quatro décadas em Portugal [From private to public: The paths of gender equality in the last four decades in Portugal]. In Revolução e Democracia 40 Anos Após Abril de 1974. Edited by lvaro Borralho. Vila Nova de Famalicão: Húmus, pp. 207-27.

Lisboa, Manuel, Zélia Barroso, Joana Patrício, and Alexandra Leandro. 2009. Violência e Género_Inquérito Nacional Sobre a Violência Exercida Contra Mulheres e Homens; Violence and gender-National survey on violence against women and men. Lisboa: Comissão para a Cidadania e Igualdade de Género.

Machado, Carla, Sónia Caridade, and Carla Martins. 2010. Violence in juvenile dating relationships: Self-reported prevalence and attitudes in Portuguese sample. Journal of Family Violence 24: 43-52. [CrossRef]

Moore, Angela, Krysten Sargenton, Dina Ferranti, and Rosa Gonzalez-Guarda. 2015. Adolescent dating violence: Supports and barriers in accessing services. Journal of Community Health Nursing 32: 39-5. [CrossRef]

Neves, Sofia, Miguel Cameira, Manuel Machado, Vera Duarte, and Fernando Machado. 2016. Beliefs on marital violence and self-reported dating violence: A comparative study of Cape Verdean and Portuguese adolescents. Journal of Child and Adolescent Trauma 11: 197-204. [CrossRef] [PubMed]

Pinheiro, Inês, and Sónia Caridade. 2019. Help seeking in dating violence victims: A systematic review. Portuguese Journal of Behavioral and Social Research 5: 68-84.

Pinto, Mariana. 2018. Permanecer, Abandonar ou Retomar à Relação Abusiva: Perceções de Mulheres Vítimas de Violência Conjugal [Stay, Leave or Return to Abusive Relationships: Victims Women Perceptions of Marital Violence]. Porto: Porto University.

Romito, Patrizia, and Michele Grassi. 2007. Does violence affect one gender more than the other? The mental health impact of violence among male and female university students. Social Science E Medicine 65: 1222-34.

Rosen, Karen, and Sandra Stith. 1995. Women terminating abusive dating relationships: A qualitative study. Journal of Social and Personal Relationships 12: 155-60. [CrossRef]

Rueda, Heidi Adams, Lela Rankin Williams, and Julie L. Nagoshi. 2015. Help-seeking and help-offering for teen dating violence among acculturating Mexican American Adolescents. Children, and Youth Services Review 53: 219-28. [CrossRef]

Sabina, Chiara, and Lavina Ho. 2014. Campus and college victim responses to sexual assault and dating violence: Disclosure, service utilization and service provision. Trauma, Violence, E Abuse 15: 201-26.

Santos, Ana, and Sónia Caridade. 2017. Violence in intimate relationship between same- sex partners: Prevalence study. Trends in Psychology 25: 1357-71. [CrossRef] 
Shen, April Chiung-Tao. 2011. Cultural barriers to help-seeking among Taiwanese female victims of dating violence. Journal of Interpersonal Violence 26: 1343-65. [CrossRef]

Shorey, Ryan, Jeniimarie Febres, Hope Brasfield, and Gregory Stuart. 2012. Male dating violence victimization adjustment: The moderating role of coping. American Journal of Men's Health 6: 218-28. [CrossRef]

Straus, Murray. 2004. Prevalence of violence against dating partners by males and female university students worldwide. Violence against Women 10: 790-811. [CrossRef]

World Health Organization. 2016. Violence against Women: Intimate Partner Violence and Sexual Violence against Women. Available online: http://www.who.int/mediacentre/factsheets/fs239/en/ (accessed on 4 April 2020).

(C) 2020 by the authors. Licensee MDPI, Basel, Switzerland. This article is an open access article distributed under the terms and conditions of the Creative Commons Attribution (CC BY) license (http://creativecommons.org/licenses/by/4.0/). 